\title{
Treatment of latrogenic esophageal perforation: Do we need another tool?
}

Authors

Institution
Marc Barthet, Jean-Michel Gonzalez

Endoscopy Unit, North Hospital, Assistance publique des Hôpitaux de Marseille, Aix Marseille University, Marseille, France

\section{Bibliography}

DOI http://dx.doi.org/

10.1055/s-0034-1393127

Published online: 8.10.2015

Endoscopy International Open 2015; 03: E552-E553

(c) Georg Thieme Verlag KG

Stuttgart - New York

E-ISSN 2196-9736

\section{Corresponding author} Marc Barthet

Endoscopy Unit, North Hospital, Assistance publique des Hôpitaux de Marseille, Aix Marseille University 13915 Marseille Cedex 20 France

marc.barthet@ap-hm.fr

\section{License terms}

()(1) $\Theta \circledast$
In this issue, Gunnar Loske et al from Hambourg (Germany) reported their experience in 10 patients with esophageal perforations endoscopically managed by Endovacuum Therapy (EVT) [1]. They achieved complete healing in all patients.

Esophageal perforations are one of the worst iatrogenic perforations that can occur, [2] and really frightening to endoscopists (and cardiologists). Esophageal perforations occur mainly after endoscopic dilatation performed for peptic strictures, malignant strictures, achalasia, anastomotic strictures, and foreign body retrieval, roughly with a rate ranging from $0 \%$ to $3 \%$ [3]. Other cases can occur after endoscopic submucosal dissection, with a mean rate of $2.4 \%$, or after passage of transesophageal blind echocardiography probes, a setting in which the complication is not so rare $[2,3]$. However, mortality related to esophageal perforations is high, with a pool mortality of $11.9 \%$ with either conservative or surgical management and with a long mean hospital stay of 32.9 days [3]. It has been established that early recognition of the esophageal perforation is vital and management after 24 hours is clearly associated with an increased rate of mortality $[2,3]$. What weapons are available to endoscopists for management of such perforations? First, we have to underscore that, to achieve the best outcomes, endoscopic treatment must be performed within the first 24 hours so as to avoid mediastinitis or pleural effusion that may require prior surgical drainage. Second, it is not acceptable to perform or to attempt any endoscopic closure without the use of $\mathrm{CO}^{2}$ insufflation. Air insufflation is associated with pneumomediastinum, subcutaneous emphysema, diffusion of infection in surrounding tissue, and impaired respiration. The endoscopist can choose the best procedure for performing endoscopic closure based largely on the size of the perforation $(25 \mathrm{~mm}$ being inaccessible to regular clips) or the location (under the crico-phar- yngeal sphincter being the most difficult location for insertion of a stent or clipping).

Recent recommendations from the European Society of Gastrointestinal Endoscopy (ESGE) suggest treating perforations $<10 \mathrm{~mm}$ with TTS clips, treating perforations ranging from 10 to $25 \mathrm{~mm}$ with OTSC clips, and larger perforations with temporary fully covered self-expanding metallic stents (SEMS) [3]. However, adequate placement of TTS clips for full thickness repair is not so simple. Fully covered stents have a high migration rate and for perforation located in the esogastric junction, ESGE advises use of partially covered SEMS, which canbe retrieved by the stent-instent technique. In two small retrospective series, EVT has been advocated for managing esophageal perforations and found more effective than SEMS or surgery [4,5]. In addition, it may be more effective for delayed management because the permanent suction can retrieve bacterial agents or saliva. Other series have shown also shown that EVT is efficient for management of colorectal fistula following surgery, with success rates ranging from $75 \%$ to $88 \%[6,7]$. However the real place for EVT in the management of esophageal perforation was not clearly elucidated in the ESGE guidelines [3].

This series reported the results of EVT management in 10 patients. EVT was performed immediately after diagnosis and always within 24 hours. Interestingly, in six cases out of 10 , the perforation was in a location difficult to manage endoscopically, four at the level of the cricopharyngeal sphincter and two at the esophagogastric junction. Drainage was removed within the first 2 to 5 days by simple oral withdrawal; 15 placement procedures were ultimately required. All the patients were cured within 3 to 7 days with no need for surgery, other endoscopic interventions or external thoracic drainage. The pattern of the tissue after removal of the foam showed typical 
granulation tissue then re-epithelialization at follow-up endoscopy.

Although this was a small and retrospective study, the series yielded very attractive resuts. All the patients were cured within 1 week without requiring other management. Infection seemed to have been under control and at follow up, there was no evidence of stenosis. Although 15 endosopic procedures were required, that does not appear to be more than would be required with management using a stent. Therefore, EVT appears to be a costeffective form of endoscopic management that should be compared to OTSC closure. EVT appears to be possible for perforations in all esophageal locations, which is a real advantage. The only problem may be the immediate availability of endoscopic vacuum devices in case of perforation. Perhaps one of these devices should always be available in every Endoscopy Unit. We could suggest to our institutions that EVT is also helpful in colorectal fistula after surgery, during the course of Crohn's disease, or for treatment of walled-off pancreatic necrosis.

\section{Competing interests: None}

\section{References}

1 Loske G, Schorsch T, Dahm C et al. latrogenic perforation of esophagus successfully treated with Endoscopic Vacuum Therapy. EIO 2015: epub ahead of print

2 Biancari F, D'Andrea $V$, Paone $R$ et al. Current treatment and outcome of esophageal perforations in adults : a systematic review and meta-analysis of 75 studies. World J Surg 2013; 37: $1051-1059$

3 Paspatis GA, Dumonceau JM, Barthet $M$ et al. Diagnosis and management of iatrogenic endoscopic perforations : position Statement from the European Society of gastrointestinal Endoscopy (ESGE). Endoscopy 2014; 46: 1 - 19

4 Brangewitz M, Voigtlander T, Helfritz FA et al. Endoscopic closure of esophageal intrathoraic leaks : stent versus endoscopic vacuum assisted therapy. Endoscopy 2013; 45: $433-438$

5 Schienewind B, Schafmayer C, Voehrs $G$ et al. Endoscopic endoluminal vacuum therapy is superior to other regimens in managing anastomotic leakage after esophagectomy : a comparative retrospective study. Surg Endosc 2013; 27: 3883 - 3890

6 Von Bernstoff W, Glitsch A, Screiber A et al. ETVARD (endoscopic transanal vacuum-assisted rectal drainage) leads to complete but delayed closure of extraperitoneal rectal anastomotic leakage cavities following neoadjuvant radiochemotherapy. Int J Colorectal Dis 2009; 24: $819-825$

7 Srinivasamurthy $D$, Wood C, Slater $R$ et al. An initial experience using transanal vacuum therapy in pelvic anastomotic leakage. Tech Coloproctol 2013; 17: 275-281 